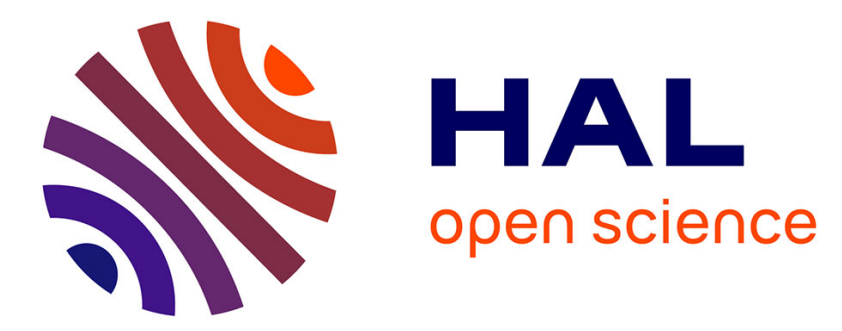

\title{
Extraction of polycyclic aromatic hydrocarbons from cookies: A comparative study of ultrasound and microwave assisted procedures
}

Gracia F Hernandez-Poveda, Angel Morales-Rubio, Agustin Pastor, Miguel de La Guardia

\section{To cite this version:}

Gracia F Hernandez-Poveda, Angel Morales-Rubio, Agustin Pastor, Miguel de La Guardia. Extraction of polycyclic aromatic hydrocarbons from cookies: A comparative study of ultrasound and microwave assisted procedures. Food Additives and Contaminants, 2008, 25 (03), pp.356-363. 10.1080/02652030701616017 . hal-00577425

\section{HAL Id: hal-00577425 \\ https://hal.science/hal-00577425}

Submitted on 17 Mar 2011

HAL is a multi-disciplinary open access archive for the deposit and dissemination of scientific research documents, whether they are published or not. The documents may come from teaching and research institutions in France or abroad, or from public or private research centers.
L'archive ouverte pluridisciplinaire HAL, est destinée au dépôt et à la diffusion de documents scientifiques de niveau recherche, publiés ou non, émanant des établissements d'enseignement et de recherche français ou étrangers, des laboratoires publics ou privés. 


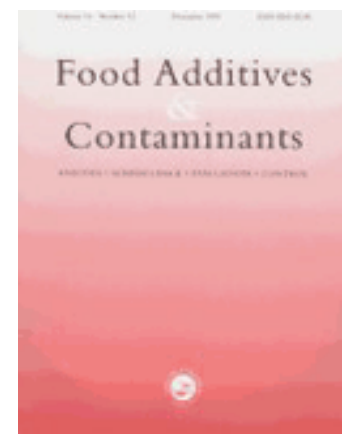

\section{Extraction of polycyclic aromatic hydrocarbons from cookies: \\ A comparative study of ultrasound and microwave assisted procedures}

\begin{tabular}{|c|c|}
\hline Journal: & Food Additives and Contaminants \\
\hline Manuscript ID: & TFAC-2007-234.R1 \\
\hline Manuscript Type: & Original Research Paper \\
\hline $\begin{array}{r}\text { Date Submitted by the } \\
\text { Author: }\end{array}$ & $17-J u l-2007$ \\
\hline Complete List of Authors: & $\begin{array}{l}\text { Hernandez-Poveda, Gracia; Universitat de Valencia } \\
\text { Morales-Rubio, Angel; Universitat de Valencia, Analytical Chemistry } \\
\text { Pastor, Agustin; Universidad de Valencia, Analytical Chemistry } \\
\text { de la Guardia, Miguel; Universidad de Valencia, Analytical } \\
\text { Chemistry }\end{array}$ \\
\hline Methods/Techniques: & Chromatography - HPLC, Extraction \\
\hline Additives/Contaminants: & $\mathrm{PAH}$ \\
\hline Food Types: & Biscuits \\
\hline
\end{tabular}

\section{SCHOLARONE ${ }^{\text {M }}$ Manuscripts}




\section{Extraction of polycyclic aromatic hydrocarbons from cookies:}

\section{A comparative study of ultrasound and microwave assisted} procedures

G.F. Hernández-Póveda, A. Morales-Rubio*, A. Pastor-García and M. de la Guardia

Department of Analytical Chemistry,

University of Valencia,

Dr. Moliner 50,

46100 Burjassot,

Valencia (Spain).

*Corresponding author: E-mail: angel.morales@uv.es 


\begin{abstract}
The chromatographic determination of 15 Polycyclic Aromatic Hydrocarbons (PAHs) in cookies has been improved in order to obtain a fast method with a low limit of detection through the combination of Microwave Assisted Extraction (MAE), oil saponification and solid phase extraction clean-up prior to the injection of purified extracts in a C18 201TP52 (5 $\mu \mathrm{m}, 250 \mathrm{~mm} \times 2.1 \mathrm{~mm})$ column. Using acetonitrile:water as mobile phase, with a $50 \%$ to $95 \% \mathrm{w} / \mathrm{w}$ acetonitrile gradient for a fixed flow of $0.250 \mathrm{ml} \mathrm{min}^{-1}, 15 \mathrm{PAHs}$ were separated in $45 \mathrm{~min}$. The column temperature was maintained at $15^{\circ} \mathrm{C}$ and fluorimetric detection was made at a fixed excitation wavelength of $264 \mathrm{~nm}$ and emission measurements at the best wavelength for each analyte, from $352 \mathrm{~nm}$ for $11 \mathrm{H}$-benzo[b]fluorene to $500 \mathrm{~nm}$ for Indeno[1,2,3cd]pyrene. Recoveries for all 15 PAHs varied between $96 \pm 4$ and $105 \pm 4 \%$, and the limits of detection ranged from $0.015 \mathrm{ng} \mathrm{g}^{-1}$ for chrysene to $0.7 \mathrm{ng} \mathrm{g}^{-1}$ for phenantrene. Results were compared with those obtained by conventional Soxhlet extraction during 8 hours refluxing with toluene, demonstrating that the methodology proposed is appropriate to quantify PAHs in cookies. Furthermore, the microwave assisted method was faster and used less solvent than the conventional and ultrasound assisted methods. The extraction time has been reduced to 9 min compared to the 8 hours required for Soxhlet extraction and $60 \mathrm{~min}$ required for ultrasound assisted treatment, and the solvent consumption has been reduced to 25 $\mathrm{ml}$ compared to the $155 \mathrm{ml}$ and $90 \mathrm{ml}$ required using Soxhlet and ultrasound respectively.
\end{abstract}

Keywords: PAHs, MAE, cookies, HPLC, fluorimetric detection. 


\section{Introduction}

Polycyclic Aromatic Hydrocarbons (PAHs) are formed by the incomplete combustion of organic matter, at temperatures between 400 and $2000^{\circ} \mathrm{C}$, anthropogenic processes being the main sources of these compounds in the environment (Swetman et al. 1999, Mclntosh et al. 2004). The carcinogenic characteristic of PAHs (Commission Regulation 2005), together with their lipophilic nature that favours accumulation in fats, justifies the careful analytical control of these compounds in human food (Larsen and Poulsen 1987, European Union 2002).

PAHs are present in foods but especially in oils and fats, the possible contamination source being deposition from air, drying processes for vegetable materials or solvents employed during oil extraction (Welling and Kaandorp 1986, Moret and Conte 2000), and therefore it is necessary to get knowledge of different PAHs in food.

European legislation has established maximum limits for benzo[a]pyrene in several food categories (Commission Regulation 2005). A recent overview of European Union legislation on PAHs and analytical methods for official control of food and environmental samples concluded that it is necessary to have harmonization between legislation of different countries and development of well established and validated methods and standardization of procedures to establish databases for the PAH monitoring in food (Wenzl et al. 2006). The Spanish regulation limits to $2 \mathrm{ng} \mathrm{g}^{-1}$ the concentration of benzo[a]pyrene, benzo[e]pyrene, benz[a]anthracene, benzo[kffluorantene, dibenz[a,h]anthracene, benzo[ghi]perylene, indeno[1,2,3$c d]$ pyrene and benzo[bffluorantene in the olive pomace oil, being limited the total concentration of these eight compounds to $5 \mathrm{ng} \mathrm{g}^{-1}$ (Spanish Official Bulletin 2001). 
The German Society for Fat Science has fixed a limit of $5 \mathrm{ng} \mathrm{g}^{-1}$ for the sum of heavy PAHs and $25 \mathrm{ng} \mathrm{g}^{-1}$ for the sum of heavy and light PAHs in oil (Speer et al 1990, Gertz and Kogelheide 1994).

Since many manufactured products contain oils or fats, it is necessary to improve the analytical methodologies for the fast, accurate and sensitive determination of PAHs in this type of products. GC and HPLC have been widely used for PAHs determination in edible fats and oils (Lawrence et al 1986, Larsson et al 1987, Speer et al 1990, Guillen 1994, Cejpek et al 1995, Moret and Conte 2000). PAH extraction has been usually carried out by liquid-liquid partition with dimethylformamide-watercyclohexane (Lawrence et al 1986, Speer et al 1990) or with dimethylsulfoxidecyclohexane (Guillen 1994) for GC analysis, or with acetonitrile for the quantitative extraction from pomace oil for HPLC analysis (Martinez-Lopez et al. 2005).

The main advantages offered by HPLC compared with GC are that: 1) it can provide additional selectivity and give separation of PAHs isomers, which are difficult to separate using GC; 2) provides an useful fractionation technique for the isolation of $\mathrm{PAH}$ for subsequent analysis by other techniques (de Boer and Law 2003); and 3) heat-sensitive compounds are not degraded during analysis (Cejpek et al 1995, de Boer and Law 2003).

Traditional sample preparation procedures based on liquid-liquid or solid-liquid extraction (Moret and Conte 1998, Toledo and Camargo 1998) or saponification (Gertz and Kogelheide 1994, Arens and Gertz 1996), are time and solvent consuming, and are inadequate for a rapid and environmentally friendly determination of PAHs. Microwave assisted treatment reduces the extraction time 
without decomposition of PAHs and uses small solvent volumes, thus reducing sample contamination. Additionally, the use of closed reactors avoids losses of volatile compound (Pastor et al 1997).

In the present study microwave-assisted extraction (MAE), using different solvents has been applied to the determination in cookies of 15 PAHs of which 12 were highlighted by the US Environmental Protection Agency (EPA 1999), and 8 were identified by the Scientific Committee of Food as carcinogenic compounds (European Commission 2002). Results found were in good agreement with those obtained by conventional Soxhlet extraction with toluene and ultrasound-assisted extraction. So, one of the objectives of this study was to provide an appropriate tool for the quantification of PAHs in manufactured products suitable for consumers and inspection laboratories for which the separate ingredients of the cookies are not accessible.

\section{Materials and Methods}

Apparatus and material.

An Agilent 1100 Series HPLC system (Waldbronn, Germany) equipped with a manual injection valve 7725i Rheodyne (Rohnert Park, CA, USA) with $20 \mu$ sample loop, a pump G1311A QUAT PUMP, a column oven G1316A COL COM, a solvent degassing system and a molecular fluorescence G1321A FLD detector, all those from Agilent, was used in this study. For PAHs separation and quantification a C18 201TP52 (5 $\mu \mathrm{m}, 250 \mathrm{~mm} \times 2.1 \mathrm{~mm}$ ) Vydac (Columbia, MD, USA) column, a guard column 201TP (5 $\mu \mathrm{m}, 2.1 \mathrm{~mm})$ from Vydac and a signal processor Chem Station HP 
from Hewlet Packard (Waldbronn, Germany) were employed. The experimental conditions employed for PAHs separation and detection are indicated in Table I.

[Insert Table I about here]

For sample preparation a IKA M20 Universe Mill (Staufen, Germany), a Büchi R 200 rotary evaporator with a water heating bath Büchi B 490 (Flawie, Switzerland), a Volter-velp shaker from Scientific (Milano, Italy), a Hermle Z 200 A Centrifuge (Wehingen, Germany), an ultrasound water bath from Selecta (Barcelona, Spain) and a microwave oven LG model MS-197H (Manchester, UK) were employed.

All the glassware material was cleaned with water and soap and stored for 8 hours with saturated $\mathrm{K}_{2} \mathrm{Cr}_{2} \mathrm{O}_{7}$ in $\mathrm{H}_{2} \mathrm{SO}_{4}$ solution, rinsed with distilled water and dried at $350^{\circ} \mathrm{C}$ for 8 hours. Plastic syringes were cleaned with water and soap, rinsed with distilled water and stored for 5 hours with acetonitrile.

Reagents and standards.

$50 \mu \mathrm{g} \mathrm{g}^{-1}$ stock solutions of PAHs were prepared, in toluene, from the corresponding solid compounds obtained from Fluka Chemika (Buchs, Switzerland) for Phenanthrene $>97.0 \%$ HPLC, Anthracene $>99.0 \%$ GC, Pyrene $>99.0 \%$ GC and Benz[a]anthracene >98 \% GC-HPLC; Aldrich Chemie (Milwaukke, USA) for Fluoranthene $99 \%$, 11H-benzo[b]fluorene >98.0 \% HPLC, Chrysene $95 \%$, Benzo[b]fluoranthene $98 \%$, Dibenz[a,c]anthracene $97.0 \%$ and Benzo[a]pyrene $>96.0 \%$ HPLC; Sigma Chemical Company (St.Louis, MO, USA) for Dibenz[a,h]anthracene $97 \%$ and AccuStandard (New Haven, CT, USA) for Benzo[kffluoranthene $98 \%$, Benzo[e]pyrene $99 \%$, Benzo[ghi]perylene $>98.0 \%$ GC 
and Indeno[1,2,3-cd]pyrene $98 \%$, making a special caution on the handle of solid products by using mask and gloves in order to avoid their hard toxic action on the operators.

Diluted multi-component standards, containing $1 \mu \mathrm{g} \mathrm{g}^{-1}$ of each one of the compounds considered, were prepared in acetonitrile from the stock solutions. Finally, standard calibration solutions, from 1 to $20 \mathrm{ng} \mathrm{g}^{-1}$, were prepared in acetonitrile from the multi-component solution. HPLC grade acetonitrile $(d=0.78 \mathrm{~g}$ $\left.\mathrm{ml}^{-1}\right)$ of $99.85 \%$ purity, Toluene for pesticide residue analysis $\left(\mathrm{d}=0.87 \mathrm{~g} \mathrm{ml}^{-1}\right)$ of 99.8 $\%$ purity and $n$-hexane for pesticide residue analysis $\left(d=0.66 \mathrm{~g} \mathrm{ml}^{-1}\right)$ were obtained from Scharlau (Barcelona, Spain). Ultrapure water was obtained with a resistivity of 18.2 M $\Omega \mathrm{cm}$ with a Millipore MilliQ plus system (Paris, France).

\section{Sample preparation.}

To carry out the study of different parameters of the extraction from cookies for PAHs determination it was employed a sample pool (400 g), obtained from eight different trade mark cookies (50 g each) with fat content between $9.2 \%$ and $21.0 \%$. Samples were stored shelter from humidity, light and heat sources.

\section{Soxhlet extraction.}

Five grams, accurately weighted in analytical balance $( \pm 0.1 \mathrm{mg})$, of the pool sample were weighted and transferred inside the Soxhlet system. $155 \mathrm{ml}$ of toluene were added and extraction process was carried out during eight hours by 48 cycles of 10 minutes. In the last cycle solvent volume was reduced to $25 \mathrm{ml}$ and passed to a conical bottom test tube to evaporate it on the rotary evaporator. Results from this 
conventional procedure were considered to establish the reference values of fat and PAHs in this pool.

\section{Ultrasound assisted extraction.}

Five grams, accurately weighted in analytical balance $( \pm 0.1 \mathrm{mg})$, of the pool sample were weighted on an erlenmeyer and between 10 to $35 \mathrm{ml}$ of solvent were added. The mixture was sonicated in the ultrasound water bath for $20 \mathrm{~min}$ and the solvent was passed to a conical bottom test tube to evaporate it on the rotary evaporator. This extraction-evaporation process was repeated three times for each sample using different portions of pure solvent, and extracts for each sample pooled.

\section{Microwave assisted extraction.}

Five grams, accurately weighted in analytical balance $( \pm 0.1 \mathrm{mg})$, of the pool sample were weighted and transferred into a $115 \mathrm{ml}$ PTFE reactor. $10 \mathrm{ml}$ of toluene and $1 \mathrm{ml}$ distilled water or $10 \mathrm{ml}$ of an acetone:hexane (1:1) mixture were added to the sample and the reactor, hermetically closed, was irradiated at $700 \mathrm{w}$ power during 3 to 15 minutes. Between the heating cycles, the reactor was maintained inside the microwave oven for $1 \mathrm{~min}$ without irradiation. After the extraction process, the reactor was cooled in an ice bath during $5 \mathrm{~min}$, then, it was opened and $8 \mathrm{~g}$ of anhydrous $\mathrm{Na}_{2} \mathrm{SO}_{4}$ were added to retain water. The solvent was passed to a conical bottom test tube to evaporate it on the rotary evaporator. Three aliquots of $5 \mathrm{ml}$ solvent were added to the reactor after extraction, mixed with sample and transferred to a centrifuge test tube to collect all oil that could be on the reactor wall and sample surface and the solvent was evaporated on the rotary evaporator.

\section{Blank preparation.}


For each extraction method analytical blanks were prepared for pure water and solvents following the same treatment than that employed for samples.

\section{Extracts clean-up through liquid extraction and solid phase purification.}

Cookies extracts obtained by the different ways indicated above, that contain approximately $1 \mathrm{~g}$ of oil, were mixed with $10 \mathrm{ml}$ acetonitrile to extract the PAHs from the fatty matrix. The mixture was shaken rigorously for $3 \mathrm{~min}$ in a volter shaker and allowed to stand for $5 \mathrm{~min}$ in an ice bath. After that, it was centrifuged at $3500 \mathrm{rpm}$ for 10 min. The upper layer was separated and further evaporated. Ten ml acetonitrile were added to the remaining oil, and the liquid extraction was repeated. After 3 extraction steps, the mixture of acetonitrile extracts was evaporated to dryness. The residue obtained after acetonitrile evaporation was dissolved in $1 \mathrm{ml}$ hexane and to remove any rest of oil, it was saponified with $100 \mathrm{mg}$ solid $\mathrm{NaOH}$. Solid phase extraction, using a Sep Pack Silica Plus cartridge from Waters (Milford, MA, USA), was employed to clean the hexane layer solution. To do it, the cartridge was conditioned by passing $1 \mathrm{ml}$ methanol and after that hexane extracts were loaded at a flow rate of $1 \mathrm{ml} \mathrm{min}^{-1}$, being cleaned the cartridges with $1 \mathrm{ml}$ of hexane. After that, hexane was evaporated and the residue dissolved in $1 \mathrm{ml}$ acetonitrile, being filtered through a $0.22 \mu \mathrm{m}$ nylon filter. A volume of $20 \mu \mathrm{l}$ of the acetonitrile solution was injected in the chromatographic system for PAHs determination.

Chromatographic method.

An acetonitrile (ACN) gradient of $0 \min 50 \%$ ACN, $7 \min 50 \%$ ACN, $20 \min 80 \%$ ACN, $25 \min 80 \%$ ACN and 30 min $95 \%$ ACN with a $0.250 \mathrm{ml}$ min-1 mobile phase flow and $15 \mathrm{C}$ column temperature was used to perform the chromatographic 
separation of PAHs under study. By using a fixed excitation wavelength of $264 \mathrm{~nm}$ the best emission wavelength, indicated in table I, were employed for quantification.

\section{Results and discussion.}

Soxhlet extraction.

Table II shows the concentration, in ng $(\mathrm{PAH}) / \mathrm{g}$ (cookie), of the $15 \mathrm{PAHs}$ studied in the pooled sample. Results obtained are the average of 4 independent analyses and have been taken as a reference, to evaluate microwave and ultrasound assisted extractions.

[Insert Table II about here]

\section{Ultrasound assisted extraction.}

Preliminary experiments using ultrasound extraction were carried out to choose the optimum solvent, evaluating $30 \mathrm{ml}$ of toluene and $30 \mathrm{ml}$ acetone-hexane $(1: 1)$ mixture. Recoveries with toluene were between $43 \%$ and $80 \%$ as compared with Soxhlet extraction, being better than those obtained by using acetone-hexane with recoveries ranging from $86 \%$ to $105 \%$.

Using acetone-hexane the effect of the solvent volume on the recovery of PAHs maintaining constant a total extraction time of 1 hour ( 3 times 20 min). As can be seen, Table III shows that the recovery of PAHs increases with increased solvent volume, but no differences in mean recovery were found between 30 and $35 \mathrm{ml}$. Furthermore, for six of the PAHs, recoveries lower than $90 \%$ were achieved and because of that, on spite of the reduction of solvent consume and extraction time as 


\author{
compared with Soxhlet extraction, this procedure cannot be considered as an \\ efficient alternative.
}

[Insert Table III about here]

Microwave extraction.

Table IV shows the recovery data of PAHs from the pooled cookies employing different irradiation times. As can be seen, 2 steps of 7.5 min were necessary to achieve the quantitative recovery of all considered compounds, as compared with those obtained by Soxhlet, when $10 \mathrm{ml}$ toluene and $1 \mathrm{ml}$ water were employed.

[Insert Table IV about here]

In order to reduce the microwave irradiation time, a polar solvent should be used. Because of that, additionally than the toluene:water mixture, an acetone-hexane $(1: 1)$ mixture was used. As can be seen in table IV quantitative recoveries of PAHs were achieved in only $9 \mathrm{~min}$ irradiation at $700 \mathrm{w}$. In these experiments, three $\times 3 \mathrm{~min}$ irradiation time steps were employed in order to avoid overpressure because the efficiency of heating of the acetone:hexane was higher than that obtained for toluene:water.

Figures of merits of the PAHs determination in cookies.

Results obtained for the 15 PAHs provided in all cases sensitive and linear regression graphs from $0.5 \mathrm{ng} \mathrm{g}^{-1}$ to $20 \mathrm{ng} \mathrm{g}^{-1}$ using 5 standards and being found regression coefficient higher than 0.9997 . For the three procedures indicated in the experimental section, the limit of detection for each one of the 15 PAHs studied were 
established from the interpolation, in the corresponding calibration line, of the smallest chromatographic peak obtained at each retention time of the PAHs considering the criterion of 3 times background noise, and taken into consideration the original sample (ng PAH/g cookie). Data provided evidence that all the extraction methods employed provided comparable limit of detection values and data found (see table V) varied from $0.015 \mathrm{ng} \mathrm{g}^{-1}$ for Chrysene to $0.9 \mathrm{ng} \mathrm{g}^{-1}$ for Phenanthrene.

[Insert Table $\mathrm{V}$ about here]

Comparison of the extraction procedures.

Ultrasound assisted extraction gave comparable recovery results (see table III) to those obtained by Soxhlet for Benz[a]anthracene, Chrysene, Benzo[b]fluoranthene, Dibenz[a,c]anthracene, Benzo[k]fluoranthene, Dibenz[a,h]anthracene and Indeno[1,2,3-cd]pyrene. However, the microwave assisted treatment using both, 15 min with toluene:water or 9 min with acetone-hexane (see table IV), gave quantitative results for all the PAHs studied. Taken in consideration the microwave assisted extraction time, the recommended procedure is that based on the use of acetonehexane mixture $(1: 1)$.

The regression between data obtained by the microwave assisted extraction using acetone-hexane $(y)$ and the Soxhlet procedure $(x)$ provided an equation $y=1.0144 x$ -0.0065 , with a regression coefficient $R^{2}$ of 0.9999 , thus evidencing the good comparability of results and confirming the validity of the microwave assisted extraction procedure in front of the classical Soxhlet extraction. The paired Student's $t$ test for both groups of data was lower than the theoretical $t$ value (1.771) for a 95\% probability level and 13 degrees of freedom. So, it can be concluded that the 
accuracy of the developed procedure is comparable to that found by using classical Soxhlet extraction.

\section{Validation of the recommended extraction procedure.}

From our results the recommended extraction procedure was based on the use of microwave irradiation and the acetone:hexane mixture (1:1). Recovery studies on a pooled sample were performed to show evidence of the absence of losses or contamination during the determination of PAHs. Data found for the pooled sample spiked $(n=3)$ with known concentration of PAHs $\left(0.5 n g g^{-1}\right.$ of each PAHs), showed quantitative recoveries for the $15 \mathrm{PAHs}$ studied. The recommended procedure provided recoveries that ranged from $86 \%$ in the case of Benz[a]anthracene, Benzo[b]fluoranthene and Benzo[ghi]perylene to $110 \%$ for Phenanthrene. For the other PAHs studied the recoveries were from $95 \%$ to $105 \%$.

Analysis of samples by the recommended extraction procedure.

Table VI shows concentration of PAHs in two types of commercial cookies obtained by using the recommended procedure, microwave irradiation of samples with $10 \mathrm{ml}$ acetone-hexane mixture for 3 steps of $3 \mathrm{~min}$ at $700 \mathrm{~W}$ power. Data reported are the average of three replicate analysis of each sample.

[Insert Table VI about here]

\section{Conclusion}

The microwave-assisted procedure developed for the extraction of $15 \mathrm{PAHs}$ in cookies provided results in good agreement with those obtained by the conventional Soxhlet extraction refluxing with toluene for 8 hours. Acetone:hexane and 
toluene:water were both appropriate to achieve the quantitative extraction of all 15 PAHs. However, acetone:hexane provided quantitative recoveries in 9 min compared to the 15 min required using toluene:water. Solvent consumption is another advantage of the proposed method, compared to Soxhlet and ultrasound assisted procedures. It has been reduced to $10 \mathrm{ml}$, plus additional $15 \mathrm{ml}$ for cleaning the reactor, compared to the $155 \mathrm{ml}$ and $90 \mathrm{ml}$ employed in Soxhlet and Ultrasound procedures respectively. The limits of detection obtained by the three procedures assayed are of the same order of magnitude for all a5 PAHs.

Concerning the PAH content on the marked samples, none of the eight PAHs regulated by law was found at concentrations higher than $2 \mathrm{ng} \mathrm{g}^{-1}$ and the sum of the concentrations of the 8 heavy PAHs was lower than $5 \mathrm{ng} \mathrm{g}^{-1}$ and the sum of heavy and light PAHs was lower than $25 \mathrm{ng} \mathrm{g}^{-1}$.

\section{Acknowledgements}

Authors acknowledge the financial support of the Laboratorio de Higiene Laboral y Ambiental of the University of Valencia.

\section{References}

Arens M, Gertz C. 1996. bestimmung von polyzyklischen aromatischen kohlenwasserstoffen in ölen und fetten. Fett/Lipid 98:216-220.

Cejpek K, Hajslova J, Jehlickova Z, Merhaut J. 1995. Simplified extraction and cleanup procedure for the determination of PAHs in fatty and protein-rich matrices. International Journal of Environmental Analytical Chemistry 61:65-80. 
Commission Regulation (EC) 208/2005, 04-02-2005 amending Regulation (EC) 466/2001 as regard polycyclic aromatic hydrocarbons. Official Journal L034, 08/02/2005:3-5.

de Boer J, Law RJ. 2003. Developments in the use of the chromatographic techniques in marine laboratories for the determination of halogenated contaminants and polycyclic aromatic hydrocarbons. Journal of Chromatography A 1000:223-251

Environmental Protection Agency (EPA) of the United States of America. 1999. Compendium Method TO-13A, EPA, Cincinnati, OH, USA.

European Commission, Opinion of the Scientific Committee on Food. 2002. Available from: http://europa.eu.int/conm/food/fs/sc/scf/out153_en.pdf

European Union Health and Consumer Protection Directorate General. 2002. Opinion of the Scientific Committee on food on the risks to human health of polycyclic aromatic hydrocarbons in food. Available from http://europa.eu.int/comm/food/fs/sc/scf/index_en.html

Gertz C, Kogelheide H. 1994. Untersuchung und beurteilung von PAK in speisefetten und-ölen. Fat Science Technology 96:175-180.

Guillen MD. 1994. Polycyclic aromatic compounds: extraction and determination in food. Food Additives and Contaminants 11:669-684.

Larsen JC, Poulsen E, editors. 1987. Toxicological Aspects of Food. London: Elsevier.

Lawrence BK, Erikson AT, Cervenka M. 1986. Polycyclic aromatic hydrocarbons in foods by HPLC with fluorescence detection. International Journal of Environmental Analytical Chemistry 24:113-131.

Martinez-López S, Morales-Noe A, Pastor-Garcia A, Morales-Rubio A, de la Guardia M. 2005. Sample preparation improvement in polycyclic aromatic hydrocarbons determination in olive oils by gel permeation chromatography and 
liquid chromatography with fluorescence detection. Journal AOAC International 88:1247-1254.

Mclntosh AD, Moffat CF, Packer G, Webster L. 2004. Polycyclic aromatic hydrocarbons $(\mathrm{PAH})$ concentration and composition determined in farmed blue mussels (Mytilus edulis) in a sea loch pre- and post-closure of an aluminium smelter. Journal Environmental Monitoring 52:209-218.

Moret S, Conte LS. 1998. Off-line LC-LC determination of PAHs in edible oils and lipidic extracts. Journal of High Resolution Chromatography 21:253-257.

Moret S, Conte LS. 2000. Polycyclic aromatic hydrocarbons in edible fats and oils: occurrence and analytical methods. Journal of Chromatography A 882:245-253.

Pastor A, Vazquez E, Ciscar R, de la Guardia M. 1997. Efficiency of the microwave-assisted extraction of hydrocarbons and pesticides from sediments. Analytica Chimica Acta 344:241-249.

Spanish Official Bulletin, 2001. Order 14558, 24/07/2001 in which is established the limits of eight heavy polycyclic aromatic hydrocarbons in olive pomace oil. BOE 178:27397-23398.

Speer K, Steeg E, Horstmann P, Kühn Th, Montag A. 1990. Determination and distribution of polycyclic aromatic hydrocarbons in native vegetable oils, smoked fish products, mussels and oysters, and bream from the river Elbe. Journal of High Resolution Chromatography 13:104-111.

Swetman T, Head S, Evans D. 1999. Contamination of coconut oil by PAH. Inform 10:706-712.

Toledo MC, Camargo MSFO. 1998. Benzo(a)pireno em óleos de milho produzidos e comercializados no Brasil. Ciencia y Tecnologia de los Alimentos 18:73-76. 
1

Welling P, Kaandorp B. 1986. Determination of polycyclic aromatic hydrocarbons $(\mathrm{PAH})$ in edible vegetable oils by liquid chromatography and programmed fluorescence detection. Comparison of caffeine complexation and XAD2 chromatography sample clean-up. Zeitschrift fur Lebensmittel Untersuchung undForschung 183:111-115.

Wenzl T, Simon R, Kleiner J, Anklam E. 2006. Analytical methods for polycyclic aromatic hydrocarbons (PAHs) in food and the environment needed for new food legislation in the European Union. Trends in Analytical Chemistry 25: 716725. 


\section{Table I}

Experimental conditions employed for the separation and detection of PAHs by HPLC

\begin{tabular}{ll|l}
\hline \multicolumn{3}{l}{ Conditions for HPLC fluorimetric determination } \\
Compound & $\lambda_{\mathbf{e m}}$ (nm) $^{*}$ & $\mathbf{t}_{\mathbf{R}}$ (min) $^{\mathbf{H}}$ \\
\hline Phenanthrene & 364 & 18.2 \\
Anthracene & 402 & 20.1 \\
Fluoranthene & 444 & 22.0 \\
Pyrene & 384 & 23.4 \\
11H-benzo[b]fluorene & 352 & 26.2 \\
Benz[a]anthracene & 396 & 27.0 \\
Chrysene & 368 & 29.3 \\
Benzo[e]pyrene & 384 & 32.2 \\
Benzo[b]fluoranthene & 440 & 34.3 \\
Dibenz[a,c]anthracene & 380 & 35.6 \\
Benzo[k]fluoranthene & 450 & 36.3 \\
Benzo[a]pyrene & 404 & 37.4 \\
Dibenz[a,h]anthracene & 400 & 41.3 \\
Benzo[ghi]perylene & 416 & 42.4 \\
Indeno[1,2,3-cd]pyrene & 500 & 45.1 \\
\hline
\end{tabular}

*: An excitation wavelength of $264 \mathrm{~nm}$ was employed in all cases

$\mathbf{H}$ : The standard deviation of the retention time for 8 independent analyses in different work sessions was in all cases of the order of $\pm 0.1 \mathrm{~min}$. 


\section{Table II}

Concentration of PAHs in a cookies pool sample obtained from Soxhlet extraction with toluene.

\begin{tabular}{l|l} 
Compound & $\mathbf{C} \pm \mathbf{s}\left(\mathbf{n g ~} \mathbf{~}^{-1}\right)$ \\
\hline Phenanthrene & $9.463 \pm 0.001$ \\
Anthracene & $0.350 \pm 0.008$ \\
Fluoranthene & $1.94 \pm 0.08$ \\
Pyrene & $<$ LOD \\
11H-benzo[bffluorene & $0.123 \pm 0.003$ \\
Benz[a]anthracene & $0.80 \pm 0.03$ \\
Chrysene & $0.219 \pm 0.005$ \\
Benzo[e]pyrene & $0.24 \pm 0.03$ \\
Benzo[b]fluoranthene & $0.22 \pm 0.02$ \\
Dibenz[a,c]anthracene & $0.288 \pm 0.009$ \\
Benzo[kfluoranthene & $0.126 \pm 0.004$ \\
Benzo[a]pyrene & $0.226 \pm 0.004$ \\
Dibenz[a,h]anthracene & $0.34 \pm 0.02$ \\
Benzo[ghi]perylene & $0.114 \pm 0.001$ \\
Indeno[1,2,3-cd]pyrene & $0.093 \pm 0.009$ \\
\hline
\end{tabular}

Average \pm standard deviation $(n=4)$ 
Table III

Effect of acetone-hexane (1:1) mixture volume on the ultrasound assisted extraction of PAHs.

\begin{tabular}{|c|c|c|c|c|c|}
\hline \multirow[t]{2}{*}{ Compound } & \multicolumn{5}{|c|}{ Solvent volume $(\mathrm{ml})$ used in each step ${ }^{\star}$} \\
\hline & 10 & 20 & 25 & 30 & 35 \\
\hline & \multicolumn{5}{|c|}{$(\mathrm{R} \pm \mathrm{s}) \%^{\mathrm{H}}$} \\
\hline Phenanthrene & $64 \pm 1$ & $78 \pm 9$ & $85 \pm 3$ & $88 \pm 1$ & $88 \pm 3$ \\
\hline Anthracene & $40 \pm 1$ & $62 \pm 2$ & $84 \pm 2$ & $87 \pm 2$ & $89 \pm 1$ \\
\hline Fluoranthene & $58 \pm 2$ & $78 \pm 9$ & $86 \pm 5$ & $89 \pm 5$ & $89 \pm 1$ \\
\hline Pyrene & - & - & - & - & - \\
\hline 11H-benzo[bjfluorene & $18 \pm 9$ & $56 \pm 1$ & $78 \pm 2$ & $86 \pm 2$ & $89 \pm 1$ \\
\hline Benz[a]anthracene & $50 \pm 4$ & $75 \pm 4$ & $91 \pm 5$ & $99 \pm 1$ & $94 \pm 8$ \\
\hline Chrysene & $34 \pm 1$ & $76 \pm 4$ & $100 \pm 7$ & $104 \pm 4$ & $106 \pm 6$ \\
\hline Benzo[e]pyrene & $41 \pm 2$ & $65 \pm 4$ & $90 \pm 3$ & $95 \pm 4$ & $97 \pm 3$ \\
\hline Benzo[bjfluoranthene & $52 \pm 2$ & $74 \pm 9$ & $98 \pm 3$ & $105 \pm 2$ & $106 \pm 3$ \\
\hline Dibenz[a,c]anthracene & $55 \pm 9$ & $80 \pm 4$ & $95 \pm 8$ & $98 \pm 2$ & $97 \pm 7$ \\
\hline Benzo[kffluoranthene & $22 \pm 4$ & $69 \pm 5$ & $104 \pm 5$ & $103 \pm 6$ & $102 \pm 4$ \\
\hline Benzo[a]pyrene & $9 \pm 7$ & $45 \pm 4$ & $71 \pm 3$ & $87 \pm 3$ & $87 \pm 3$ \\
\hline Dibenz[a,h]anthracene & $15 \pm 1$ & $36 \pm 9$ & $76 \pm 3$ & $95 \pm 3$ & $97 \pm 2$ \\
\hline Benzo[ghijperylene & - & $32 \pm 3$ & $73 \pm 3$ & $86 \pm 2$ & $86 \pm 7$ \\
\hline Indeno[1,2,3-cd]pyrene & - & $37 \pm 8$ & $78 \pm 9$ & $93 \pm 6$ & $95 \pm 7$ \\
\hline Mean & $38 \pm 4$ & $61 \pm 6$ & $86 \pm 5$ & $94 \pm 3$ & $94 \pm 4$ \\
\hline
\end{tabular}

*:Total extraction time was 1 hour ( 3 steps of 20 minutes)

${ }^{H}$ :Values expressed are the recovery percentages compared with Soxhlet extraction \pm the standard deviation of 3 independent assays. 


\section{Table IV}

Effect of irradiation time on the microwave extraction of PAHs by using toluene-water and acetone-hexane mixtures.

\begin{tabular}{|c|c|c|c|c|c|c|c|c|}
\hline \multirow[t]{2}{*}{ Compound } & \multicolumn{5}{|c|}{$\begin{array}{l}\text { Toluene-water } \\
\text { Irradiation time }(\min )^{\star}\end{array}$} & \multicolumn{3}{|c|}{$\begin{array}{l}\text { acetone-hexane mixture } \\
\text { Irradiation time }(\mathrm{min})^{\star}\end{array}$} \\
\hline & \multicolumn{2}{|c|}{$1.5+1.5 \quad 3+3$} & \multirow{2}{*}{$\begin{array}{l}4.5+4.5 \\
(R \pm s) \%\end{array}$} & \multirow[t]{2}{*}{$6+6$} & \multirow[t]{2}{*}{$7.5+7.5$} & \multirow[t]{2}{*}{$3+3$} & \multirow{2}{*}{$\begin{array}{l}3+3+3 \\
(R \pm s) \%{ }^{H}\end{array}$} & \multirow[t]{2}{*}{$3+3+3+3$} \\
\hline & & & & & & & & \\
\hline Phenanthrene & $24 \pm 1$ & $49 \pm 1$ & $99 \pm 1$ & $100 \pm 4$ & $100 \pm 1$ & $62 \pm 9$ & $102 \pm 1$ & $104 \pm 1$ \\
\hline Anthracene & $56 \pm 1$ & $60 \pm 3$ & $76 \pm 3$ & $91 \pm 4$ & $104 \pm 4$ & $71 \pm 4$ & $105 \pm 3$ & $103 \pm 2$ \\
\hline Fluoranthene & $39 \pm 5$ & $63 \pm 4$ & $87 \pm 3$ & $91 \pm 4$ & $100 \pm 5$ & $58 \pm 3$ & $99 \pm 1$ & $96 \pm 1$ \\
\hline Pyrene & - & - & - & - & - & - & - & - \\
\hline 11H-benzo[b]fluorene & $21 \pm 2$ & $26 \pm 1$ & $68 \pm 8$ & $90 \pm 4$ & $102 \pm 1$ & $30 \pm 1$ & $101 \pm 1$ & $100 \pm 1$ \\
\hline Benz[a]anthracene & $65 \pm 4$ & $75 \pm 1$ & $85 \pm 2$ & $92 \pm 5$ & $100 \pm 2$ & $74 \pm 3$ & $105 \pm 4$ & $101 \pm 2$ \\
\hline Chrysene & $51 \pm 2$ & $60 \pm 2$ & $83 \pm 7$ & $101 \pm 1$ & $105 \pm 4$ & $64 \pm 2$ & $103 \pm 4$ & $100 \pm 2$ \\
\hline Benzo[e]pyrene & $36 \pm 2$ & $45 \pm 4$ & $73 \pm 3$ & $86 \pm 3$ & $99 \pm 4$ & $61 \pm 2$ & $99 \pm 3$ & $100 \pm 2$ \\
\hline Benzo[b]fluoranthene & $49 \pm 2$ & $57 \pm 3$ & $85 \pm 3$ & $91 \pm 5$ & $98 \pm 7$ & $66 \pm 9$ & $103 \pm 3$ & $98 \pm 3$ \\
\hline Dibenz[a,c]anthracene & $15 \pm 1$ & $40 \pm 4$ & $70 \pm 4$ & $91 \pm 1$ & $101 \pm 2$ & $80 \pm 1$ & $105 \pm 3$ & $99 \pm 4$ \\
\hline Benzo $[k] f l u o r a n t h e n e$ & $32 \pm 1$ & $42 \pm 6$ & $71 \pm 4$ & $91 \pm 3$ & $98 \pm 5$ & $71 \pm 3$ & $96 \pm 4$ & $100 \pm 1$ \\
\hline Benzo[a]pyrene & $12 \pm 3$ & $44 \pm 3$ & $81 \pm 4$ & $92 \pm 4$ & $104 \pm 5$ & $62 \pm 3$ & $101 \pm 3$ & $99 \pm 1$ \\
\hline Dibenz[a,h]anthracene & $4 \pm 4$ & $14 \pm 3$ & $48 \pm 5$ & $81 \pm 7$ & $96 \pm 1$ & $16 \pm 1$ & $97 \pm 9$ & $98 \pm 9$ \\
\hline Benzo[ghijperylene & - & $13 \pm 2$ & $19 \pm 2$ & $60 \pm 3$ & $98 \pm 6$ & $53 \pm 1$ & $100 \pm 2$ & $102 \pm 1$ \\
\hline Indeno[1,2,3-cd]pyrene & - & $24 \pm 1$ & $26 \pm 1$ & $65 \pm 3$ & $106 \pm 4$ & $75 \pm 6$ & $100 \pm 1$ & $99 \pm 1$ \\
\hline Mean & $34 \pm 2$ & $44 \pm 2$ & $69 \pm 4$ & $88 \pm 4$ & $101 \pm 4$ & $60 \pm 5$ & $101 \pm 3$ & $100 \pm 2$ \\
\hline
\end{tabular}

${ }^{*}$ Time in minutes correspond to each step assayed.

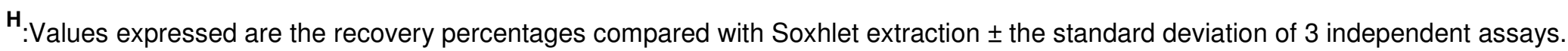


1

2

Results shown as mean \pm standard deviation of three independent analyses

a: Limit of detection in cookies ng PAHs/g cookies

b: Acetone + hexane mixture

\begin{tabular}{|c|c|c|c|c|}
\hline \multirow[b]{2}{*}{ Compound } & \multicolumn{4}{|c|}{$\begin{array}{c}\operatorname{LOD}^{\mathrm{a}} \\
\left(\mathrm{ng} \mathrm{g}^{-1}\right)\end{array}$} \\
\hline & Soxhlet & Ultrasound & $\begin{array}{c}\text { Microwave } \\
\text { (Toluene) }\end{array}$ & $\begin{array}{c}\text { Microwave } \\
(\mathrm{Ac}: \mathrm{Hx})^{\mathrm{b}}\end{array}$ \\
\hline Phenanthrene & 0.6 & 0.9 & 0.4 & 0.7 \\
\hline Anthracene & 0.09 & 0.11 & 0.12 & 0.19 \\
\hline Fluoranthene & 0.4 & 0.3 & 0.5 & 0.3 \\
\hline Pyrene & 0.4 & 0.5 & 0.4 & 0.5 \\
\hline $11 \mathrm{H}$-benzo[bffluorene & 0.015 & 0.018 & 0.019 & 0.017 \\
\hline Benz[a]anthracene & 0.2 & 0.3 & 0.3 & 0.11 \\
\hline Chrysene & 0.03 & 0.02 & 0.03 & 0.015 \\
\hline Benzo[e]pyrene & 0.18 & 0.3 & 0.2 & 0.18 \\
\hline Benzo[bffluoranthene & 0.06 & 0.09 & 0.03 & 0.03 \\
\hline Dibenz[a,c]anthracene & 0.10 & 0.13 & 0.10 & 0.19 \\
\hline Benzo[kffluoranthene & 0.07 & 0.011 & 0.015 & 0.03 \\
\hline Benzo[a]pyrene & 0.05 & 0.019 & 0.03 & 0.03 \\
\hline Dibenz[a,h]anthracene & 0.03 & 0.013 & 0.07 & 0.06 \\
\hline Benzo[ghi]perylene & 0.03 & 0.02 & 0.019 & 0.02 \\
\hline \multirow[t]{2}{*}{ Indeno[1,2,3-cd]pyrene } & 0.02 & 0.018 & 0.016 & 0.02 \\
\hline & & & 30 & \\
\hline
\end{tabular}

\section{Table V}

Limit of detection calculated for each of the tested procedures. 


\section{Table VI}

Analysis of commercial cookies by the recommended procedure.

\begin{tabular}{|c|c|c|c|c|}
\hline \multirow[b]{2}{*}{ Compound } & \multirow[b]{2}{*}{$\begin{array}{c}\text { LOD }^{1} \\
\left(\mathrm{ng} \mathrm{g}^{-1}\right)\end{array}$} & \multicolumn{3}{|c|}{ Concentration (ng g ${ }^{-1}$ ) } \\
\hline & & $\begin{array}{c}\text { Sample } 1 \\
\text { (18.5 \% oil) }\end{array}$ & $\begin{array}{c}\text { Sample } 2 \\
\text { (21.0 \% oil) }\end{array}$ & $\begin{array}{c}\text { Pool } \\
\text { (16.0\% oil) }\end{array}$ \\
\hline Phenanthrene & 0.7 & $8 \pm 2$ & $3 \pm 1$ & $9.6 \pm 0.1$ \\
\hline Anthracene & 0.19 & $0.5 \pm 0.1$ & $<$ LOD & $0.37 \pm 0.02$ \\
\hline Fluoranthene & 0.3 & $0.70 \pm 0.07$ & $0.90 \pm 0.01$ & $1.92 \pm 0.04$ \\
\hline Pyrene & 0.5 & $<$ LOD & $<$ LOD & $<$ LOD \\
\hline 11H-benzo[b]fluorene & 0.017 & $1.3 \pm 0.1$ & $0.025 \pm 0.001$ & $0.124 \pm 0.003$ \\
\hline Benz[a]anthracene & 0.11 & $0.98 \pm 0.06$ & $1.5 \pm 0.1$ & $0.81 \pm 0.05$ \\
\hline Chrysene & 0.015 & $0.22 \pm 0.05$ & $0.10 \pm 0.01$ & $0.23 \pm 0.02$ \\
\hline Benzo[e]pyrene & 0.18 & $<$ LOD & $0.2 \pm 0.2$ & $0.2 \pm 0.2$ \\
\hline Benzo[b]fluoranthene & 0.03 & $0.031 \pm 0.004$ & $0.10 \pm 0.01$ & $0.22 \pm 0.01$ \\
\hline Dibenz[a,c]anthracene & 0.19 & $0.2 \pm 0.3$ & $1.8 \pm 0.5$ & $0.30 \pm 0.02$ \\
\hline Benzo[kffluoranthene & 0.03 & $0.03 \pm 0.02$ & $0.077 \pm 0.002$ & $0.122 \pm 0.009$ \\
\hline Benzo[a]pyrene & 0.03 & $0.04 \pm 0.02$ & $<$ LOD & $0.23 \pm 0.01$ \\
\hline Dibenz[a,h]anthracene & 0.06 & $<$ LOD & $<$ LOD & $0.33 \pm 0.07$ \\
\hline Benzo[ghi]perylene & 0.02 & $0.658 \pm 0.003$ & $0.124 \pm 0.005$ & $0.114 \pm 0.005$ \\
\hline Indeno[1,2,3-cd]pyrene & 0.02 & $0.07 \pm 0.03$ & $0.208 \pm 0.006$ & $0.092 \pm 0.002$ \\
\hline
\end{tabular}

Results shown as mean \pm standard deviation of three independent analyses 1: Limit of detection in cookies. 